\title{
Evolution of the $\alpha$-Subunit of Na/K-ATPase from Paramecium to Homo sapiens: Invariance of Transmembrane Helix Topology
}

\author{
Gene A. Morrill ${ }^{1} \cdot$ Adele B. Kostellow $^{1}$ Lijun Liu ${ }^{2} \cdot$ Raj K. Gupta $^{1}$ • \\ Amir Askari ${ }^{2}$
}

Received: 6 January 2016/Accepted: 3 March 2016/Published online: 10 March 2016

(c) The Author(s) 2016. This article is published with open access at Springerlink.com

\begin{abstract}
Na} / \mathrm{K}$-ATPase is a key plasma membrane enzyme involved in cell signaling, volume regulation, and maintenance of electrochemical gradients. The $\alpha$-subunit, central to these functions, belongs to a large family of P-type ATPases. Differences in transmembrane (TM) helix topology, sequence homology, helix-helix contacts, cell signaling, and protein domains of Na/K-ATPase $\alpha$-subunit were compared in fungi (Beauveria), unicellular organisms (Paramecia), primitive multicellular organisms (Hydra), and vertebrates (Xenopus, Homo sapiens), and correlated with evolution of physiological functions in the $\alpha$-subunit. All $\alpha$-subunits are of similar length, with groupings of four and six helices in the $\mathrm{N}$ - and C-terminal regions, respectively. Minimal homology was seen for protein domain patterns in Paramecium and Hydra, with high correlation between Hydra and vertebrates. Paramecium $\alpha$-subunits display extensive disorder, with minimal helix contacts. Increases in helix contacts in Hydra approached vertebrates. Protein motifs known to be associated with membrane lipid rafts and cell signaling reveal significant positional shifts between Paramecium and Hydra vulgaris, indicating that regional membrane fluidity changes occur during evolution. Putative steroid binding sites overlapping TM-3 occurred in all species. Sites associated with G-protein-receptor stimulation occur both in vertebrates and amphibia but not in Hydra or Paramecia. The C-terminus moiety "KETYY," necessary for the $\mathrm{Na}^{+}$activation
\end{abstract}

Gene A. Morrill

gene.morrill@einstein.yu.edu

1 Department of Physiology and Biophysics, Albert Einstein College of Medicine, Bronx, NY 10461, USA

2 Department of Biochemistry and Cancer Biology, University of Toledo Health Science Campus, Toledo, OH 43614, USA of pump phosphorylation, is not present in unicellular species indicating the absence of classical $\mathrm{Na}^{+} / \mathrm{K}^{+}$-pumps. The basic protein topology evolved earliest, followed by increases in protein domains and ordered helical arrays, correlated with appearance of $\alpha$-subunit regions known to involve cell signaling, membrane recycling, and ion channel formation.

Keywords $\mathrm{Na} / \mathrm{K}$-ATPase $\alpha$-subunit - Evolution · Protein domains · Transmembrane helix $\cdot$ Cell signaling .

Helix-helix interactions

\section{Background}

$\mathrm{Na} / \mathrm{K}$-ATPase, a highly conserved integral membrane protein, is key to maintenance of both cell volume and electrochemical gradients (Kaplan 2002; Blanco 2005; Geering 2008), as well as cell signaling (Reinhard et al. 2013), has origins that go back to the prokaryotes (reviewed in Saez et al. 2010; Chan et al. 2010). Its $\alpha$-subunit, responsible for many of its known functions, belongs to a large family of P-type ATPases (reviewed in [Kaplan 2002; Bublitz et al. 2011]). The P-type ATPases, also known as E1-E2 ATPases, are a large group of evolutionarily related ion and lipid transporters that are found in bacteria, archaea, and eukaryotes (Saez et al. 2010). Each consists of bundles of 10 transmembrane (TM) $\alpha$-helices and is referred to as a P-type ATPase because they catalyze autophosphorylation of a key conserved aspartate residue within the $\alpha$-subunit. Thever and Saier (2009) analyzed the fully sequenced genomes of 26 eukaryotes for P-type ATPases and reported probable topologies and conserved motifs of 9 functionally characterized families and 13 uncharacterized families of these transporters. Studies by 
Saez et al. (2010) indicate that the likely origin of many of the P-type (subfamily IIC) proteins is prokaryotic, and that many are present in non-metazoans, such as algae, protozoans, or fungi. They also propose that early deuterostomes presented a single IIC gene, from which all the extant diversity of vertebrate IIC proteins originated by gene and genome duplications.

In this study, we compare the differences in TM helix topology, sequence homology, helix-helix contacts, cell signaling, disordered protein regions, and protein domains of $\mathrm{Na} / \mathrm{K}$-ATPase $\alpha$-subunits in several organisms: (1) Beauveria bassiana, a fungus, (2) Paramecium tetraurelia, a unicellular ciliate protozoa, (3) Hydra vulgaris, a primitive multicellular organism with two main body layers separated by a gel, and (4) both lower (Xenopus laevis) and higher vertebrates (Homo sapiens). Since the P-type ATPases appear to have evolved into multifunctional integral plasma membrane enzymes during evolution from Paramecium to $H$. sapiens, it may be possible to correlate sequential structural changes in the primitive $\mathrm{Na}^{+}$-pump (Na/K-ATPase) with the appearance of specialized functions (e.g., cellular signaling, membrane recycling) and in turn with specific sequence changes. As indicated, each $\alpha$-subunit contains about 1000 residues and 10 TM helices. Structure-function analysis indicates that evolution was due in large part to progressive increases in membrane protein domains and helix-helix interactions. Thus the basic protein topology evolved very early, followed by selective amino acid sequence changes over millions of years that resulted in a complex system that controls cell division, growth, and differentiation.

\section{Methods}

\section{Protein Sequence Sources}

The amino acid sequences of the steroid binding proteins were downloaded from the ExPASy Proteomic Server of the Swiss Institute of Bioinformatics (http://www.expasy.org; http://www.uniprot.org). About $98 \%$ of the protein sequences provided by UniProtKB are derived from the translation of the coding sequences (CDS) which have been submitted to the public nucleic acid databases, the EMBLBank/Genbank/DDBJ databases (INSDC). The present study uses the complete amino acid sequences of the $\alpha$ subunits of the Na/K-ATPase from B. bassiana (BEAB2, Accession \#J5JMV7), Paramecium tetraurelia (ATP1A_ PARTE, Accession \#Q6BGF7), $H$. vulgaris (AT1A_ HYDVU, Accession \#P35317), X. laevis (AT1A1_XENLA, Accession \#Q92123), and H. sapiens (AT1A1_HUMAN, Accession \#P05023).

\section{Secondary Structure Predictions}

TM helices were predicted using (1) MEMSAT-SVM (Nugent and Jones 2009), (http://www.bioinf.cs.ucl.ac.uk/ psipred/), (2) TMpred (Krogh et al. 2001), (http://www.ch. embnet.org/software/tmbase/TMBASF.doc,html), SPOCTOPUS algorithm (Viklund et al. 2008) (http://octo pus.cbr.su.se), and (4) MemBrain, which integrates a number of recent bioinformatic approaches including the optimized evidence-theoretic K-nearest neighbor algorithm (Shen and Chou 2008) available at http://chou.med.har vard.edu/bioinf/MemBrain/. Pore-lining regions in TM protein sequences were predicted using the method of Nugent and Jones (2012).

The contribution of intrinsic disorder to protein function and identification of functional sites in disordered regions was estimated by the method of Cozzetto and Jones (2013). Protein domain boundary prediction was estimated using the DomPred server (Bryson et al. 2007) and the Membrain server (Yang et al. 2013). The methods of Bryson et al. (2007) are available at http://bioinf.cs.ucl.ac.uk/software. html. The method of Yang et al. is available at http://www. csbio.sjtu.edu.cn/bioinf/MemBrain .

\section{TMKink: A Method to Predict Transmembrane Helix Kinks}

Meruelo et al. (2011) have identified distinct residue preferences in kinked versus non-kinked helices and have exploited these differences and residue conservation to predict kinked helices using a neural network. The kink predictor, TMKink, is available at http://tmkinkpredictor. mbi.ucla.edu/.

\section{Helical Packing Arrangement Predictions}

The MEMPACK prediction server (psipred@cs.ucl.as.uk) was used to predict lipid exposure, residue contacts, helix-helix interactions, and helical packing arrangement, in addition to TM topology. The MemBrain method (http://csbio.sjto.edu.cn/bioinf/MemBrain/) was used to derive TM inter-helix contacts from amino acid sequences by combining correlated mutations and multiple machinelearning classifiers (Yang et al. 2013). The TOPCONS web interface (http://topcons.cbr.su.se/pred/result/rst_ $\mathrm{j} 7 \mathrm{ZjE} 1$ ) allows for constraining parts of the protein sequence to a known inside/outside location to be displayed both graphically and in text format (Bernsal et al. 2009). 


\section{Results and Discussion}

\section{Comparison of Transmembrane Topology of $\mathrm{Na} / \mathrm{K}-$ ATPase $\alpha$-Subunits in Paramecia, Hydra vulgaris, and Homo sapiens}

Figure 1 compares the predicted topology of the $\alpha$-subunits of $\mathrm{Na} / \mathrm{K}-\mathrm{ATPase}$ from $H$. sapiens (top), ATP1A1, Accession \#P05023, with a primitive multicellular organism, $H$. vulgaris, (middle) AT1A_HYDVU, Accession \#P35317 and a unicellular protozoa, Paramecium tetraurelia, (bottom) AT1A_PARTE, Accession Q6BGF7, using the MemBrain Server (see Methods" section). The amino acid sequences are those for the complete proteins as published in the Swiss Protein Database (www.uniprot.org). The ordinate indicates the propensity of multiple respective helices using the MemBrain algorithm. In all three species both the $\mathrm{N}$ - and $\mathrm{C}$-terminal ends of the $\alpha$-subunit are cytoplasmic. All exhibit two helix pairs in the $\mathrm{N}$-terminal region and a second group of 6 helices in the C-terminal region. MemBrain is a machine-learning-based predictor (see Methods), which integrates of number of bioinformatics approaches, including sequence representation by multiple sequence alignment matrix, the optimized evidence-theoretic K-nearest neighbor prediction algorithm, fusion of multiple prediction window sizes, and classification by dynamic threshold. MemBrain demonstrates an improvement of about $20 \%$ accuracy in predicting the ends of TM helices, particularly for TM helices shorter than 15 residues. As noted by Shen and Chou (2008), although a significant per cent of the TM helices of known structures are either very short ( $<15$ residues) or very long ( $>40$ residues), prediction methods such as TMHMM (Krogh et al. 2001) cannot detect TM helices shorter than 16 residues or longer than 35 residues. Other algorithms [e.g., TOPCONS (2009)] assume all TM helices contain 20 residues.

As shown in Fig. 1, the MemBrain algorithm predicts 10 TM helices in H. sapiens and Hydra vulgaris but only 9 TM helices plus 2 "half helix" TMs in Paramecia (PARTE). For comparison, other servers [e.g., SPOCTOPUS, (Viklund et al. 2008) MEMSAT-SVM, (Nugent and Jones 2012) and Phobius, (Kall et al. 2007)] predict that each species contains $10 \mathrm{TM}$ helices. As can be seen, there is more variability in the $\mathrm{C}$-terminal region, with apparent shifts in position of TM helices 5, 6, and 7 during the evolution of early multicellular organisms (i.e., Paramecium to Hydra). A similar MemBrain analysis of the topology of other mammalian P-type IIC enzymes CaATPase (SERCA), H-ATPase, H/K-ATPase, and phospholipid flippase predicted that all contain $10 \mathrm{TM}$ helices, with two pairs of TM helices in the N-terminal region, and a group of 6 helices at the $\mathrm{C}$-terminal end (data not shown).

Amino acid sequences of the three proteins shown in Fig. 1 as well as the $\alpha$-subunit of the Na/K-ATPase a lower vertebrate (Xenopus laevis) were compared using the Pairwise Sequence Alignment software (LALIGN) at http:// www.ebi.ac.uk/Tools/services/web lalign to detect internal duplications by calculating non-intersecting local alignments (Huang and Miller 1991). Table 1 compares the \% identities of amino acid residues in the $10 \mathrm{TM}$ helices of $X$. laevis (column 2), H. vulgaris (column 3), and P. tetraurelia (column 4) with those of $H$. sapiens (numbers in parenthesis indicate the $\%$ amino acid similarities). There is a high correlation between $H$. sapiens and $X$. laevis. Comparison of $H$. sapiens and $H$. vulgaris also demonstrated a high correlation between the two TM helical pairs in the N-terminal region; less so within the C-terminal TM helices. On average, $P$. tetraurelia exhibited far fewer sequence correlations and displayed only $10-30 \%$ identity with $H$. sapiens in the $4 \mathrm{C}$-terminal TM helices.

The Emboss Water protocol (version 36.3.5e Nov, 2012; preload8) used here employs the Smith-Waterman algorithm (with modified enhancements) to estimate the local alignment of two sequences (Huang and Miller 1991). Comparison of $H$. sapiens and $H$. vulgaris $\alpha$-subunits revealed a Waterman-Eggert score of 4825 with $70.9 \%$ identity (88.5\% similar) in 1020 amino acid overlap (81023:14-1031). Comparison of H. sapiens and Paramecium $\alpha$-subunits indicated a Waterman-Eggert score of 2404 with $46.6 \%$ identity ( $74.0 \%$ similar) in 882 amino acid overlap (40-886:99-969).

\section{Putative Domain Boundaries in Human, Hydra, and Paramecium $\alpha$-Subunits}

The shortest sequence of amino acids in proteins that contains functional and structural information is termed a "motif," whereas a conserved part of a given protein that can evolve, function, and exist independently is termed a "domain." Domains form the structural basis of the physiological functions of proteins and each domain can be considered as a semi-independent structural unit of a protein capable of folding independently (Wetlaufer 1973; Richardson 1981; Vogel et al. 2004). A variety of different methodologies have been employed to predict domains but many are fraught with problems since domain assignment is difficult even when the structures are known. Bryson et al. (e.g., 2007) have developed a useful method for 
Fig. 1 A comparison of the topology of TM helices of Na/ K-ATPase $\alpha$-subunits of Homo sapiens (top, \#P05023), Hydra vulgaris (middle, \#P35317), and

Paramecium tetraurelia (bottom, Q6BGF7) using the MemBrain algorithm. The abscissa represents the sequence positions; the ordinate indicates the propensity of TM helices.

Plots were obtained as described in "Methods" section

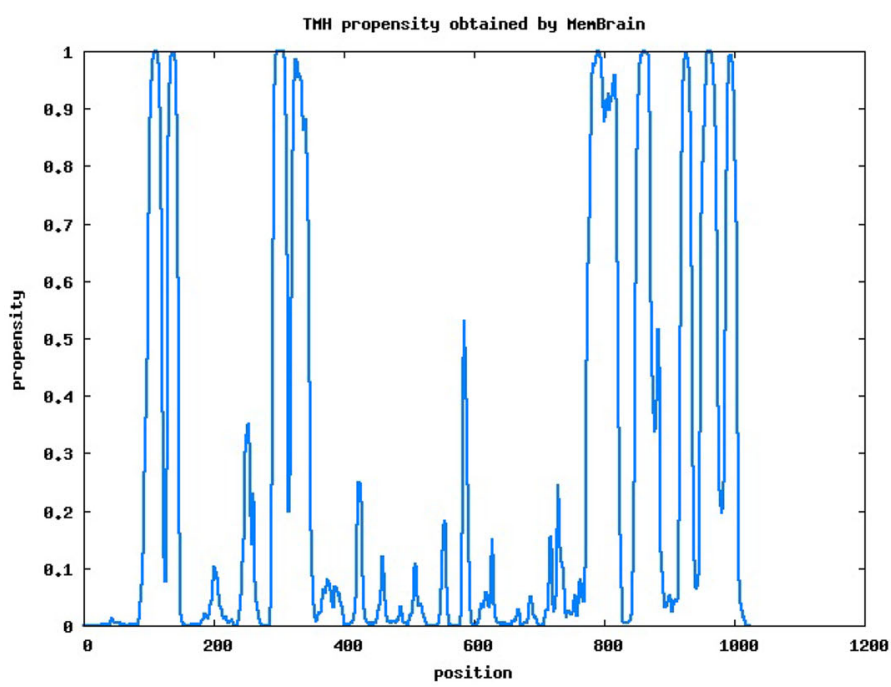

Homo sapiens

P05023

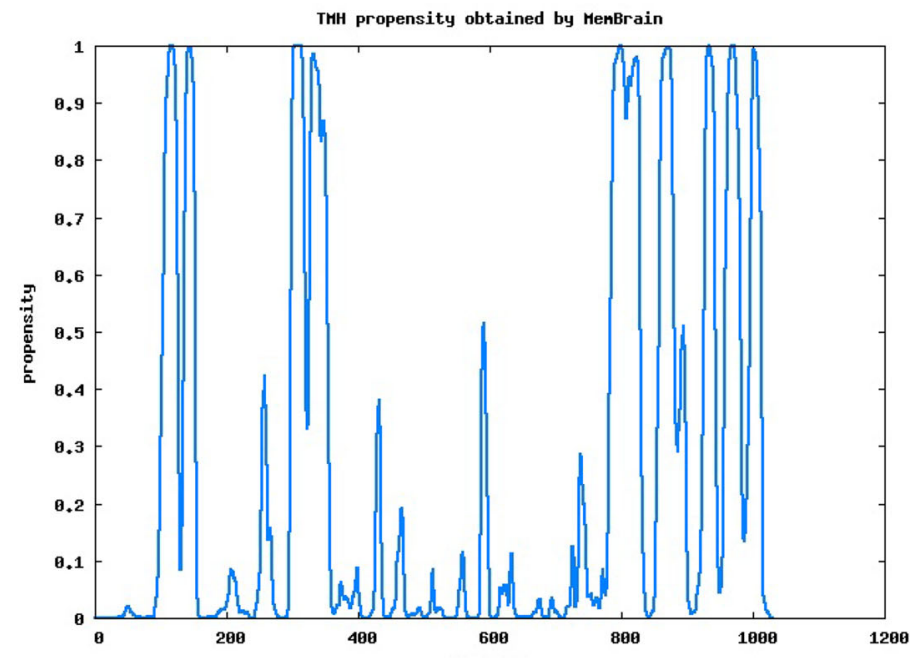

THH propensity obtained by MenBrain

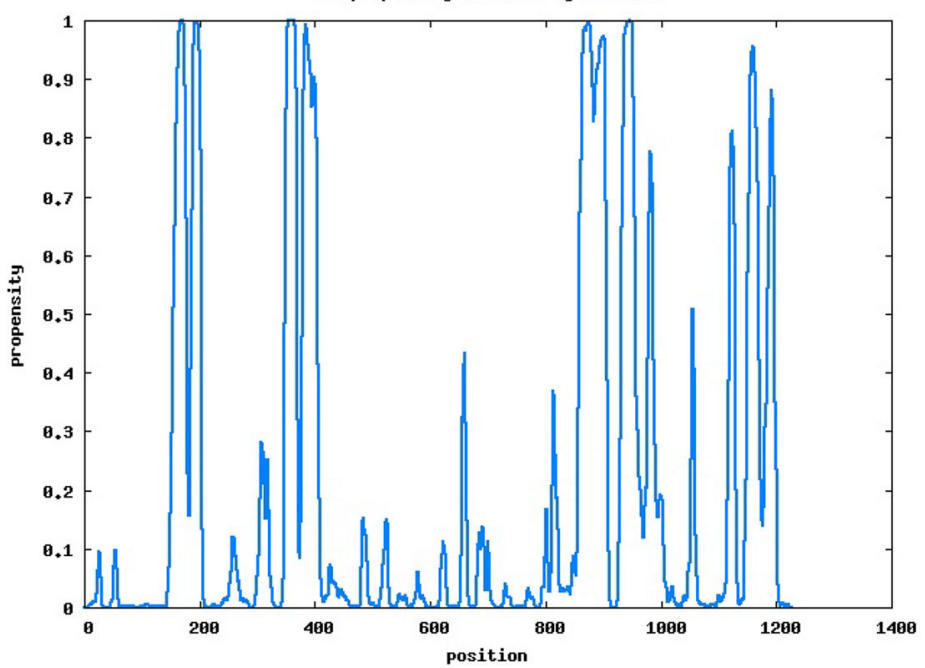

Hydra Vulgaris

P35317
Parte

(Paramecium) Q6BGF7 computer-assisted protein domain boundary prediction, using the DomPred server (see Methods). This server uses the results from two completely different categories (DPS and DomSSEA). Each is individually compared against one of the latest domain prediction benchmarks to determine their respective reliabilities. 
Table 1 Similarities between helices of the $\alpha$-subunit of Na/K-ATPase in Xenopus laevis, Hydra vulgaris, and Paramecium tetraurelia compared to Homo sapiens

\begin{tabular}{llll}
\hline Transmembrane (TM) helices & $\begin{array}{l}\text { \% Identity of amino acid sequences of individual transmembrane helices (\% Amino acid similarities indicated in } \\
\text { parenthesis) }\end{array}$ & Paramecium tetraurelia \\
\cline { 2 - 4 } & Xenopus laevis & Hydra vulgaris & 55 \\
TM-1 & 95 & 90 & $40(85)$ \\
TM-2 & 100 & 90 & $45(65)$ \\
TM-3 & 95 & 90 & $75(90)$ \\
TM-4 & 100 & 100 & $45(80)$ \\
TM-5 & 100 & $70(85)$ & $50(65)$ \\
TM-6 & 100 & 100 & $30(45)$ \\
TM-7 & 100 & $80(85)$ & $10(30)$ \\
TM-8 & $85(95)$ & 75 & $25(70)$ \\
TM-9 & 100 & 75 & $10(15)$ \\
TM-10 & $85(100)$ & 65 & \\
\hline
\end{tabular}

Figure 2 compares the domain topology of the $\alpha$-subunit of the $\mathrm{Na} / \mathrm{K}$-ATPase from $H$. sapiens (top), $H$. vulgaris (middle), and P. tetraurelia (bottom), using the DomPred server. Vertical peaks and bars indicate the positions of domains within the peptide sequence. The ordinate represents the aligned termini profile and predicts the probability of the respective domains based on the DomPred algorithm. As shown, the DomPred profiles of $H$. sapiens and $H$. vulgaris are largely identical and more complex than the aligned termini profile shown for P. tetraurelia. Compared with Hydra, Paramecium lacks domains in the 200-800 residue range. The DomPred profile of Paramecium indicates that the predominance of domains occurs in the region containing TM helices five through eight (see Fig. 1). This suggests that significant differences in helixhelix interactions may occur in this region of the $\alpha$-subunit.

\section{Evolution of $\mathrm{Na} / \mathrm{K}-\mathrm{ATPase}$ as a Signal Transducer}

Xie and Askari (2002) were among the first to show that, in addition to pumping ions, $\mathrm{Na} / \mathrm{K}$-ATPase interacts with neighboring proteins in cardiac cells to release cascades of signaling proteins which send messages to other intracellular sites. They concluded that exposure of intact cardiac cells to cardiotonic steroids such as ouabain activates growth-related cell pathways by binding to a pre-existing $\mathrm{Src}-\mathrm{Na} / \mathrm{K}-\mathrm{ATPase}$ complex. Though the existence of direct contact between $\mathrm{Src}$ and $\mathrm{Na} / \mathrm{K}-\mathrm{ATPase}$ has been seriously questioned (Reinhard et al. 2013; Weigand et al. 2012; Gable et al. 2014), the role of $\mathrm{Na} / \mathrm{K}$-ATPase as a signal transducer is now well established (Reinhard et al. 2013). To date, two ouabain-activated pathways have been identified: the EGFR/Src/Ras/ERK pathway and the P13 K1APDK-Akt pathway, both of which affect growth in a variety of cell types (Wu et al. 2013). Another signaling pathway involving $\mathrm{Na} / \mathrm{K}$-ATPase is that reported by Yudowski et al. (2000), resulting in the endocytosis of $\mathrm{Na} / \mathrm{K}$-ATPase molecules in response to $\mathrm{G}$-protein-coupled receptor stimulation of the PI3K-IA/PDK/Akt pathway. As discussed by Wu et al. (2013) and Yudowski et al. (2000), it is most likely that the interaction of the $\mathrm{Na} / \mathrm{K}$-ATPase with $\mathrm{PI} 3 \mathrm{~K} 1 \mathrm{~A}$ is direct and through the binding of the $\mathrm{SH} 3$ domains of the $\mathrm{p}-85$ subunit of PI3K1A to the proline-rich domain (TPPPTTP) of the $\alpha$-subunit of Na/K-ATPase. As shown in Table 2 (column 2), the proline-rich domain is not common in species prior to Hydra. This is consistent with the finding by Mushegian et al. (2012) that G-proteincoupled receptors apparently emerged before vertebrates and rapidly expanded in true Metazoa, probably due to the need for rapid signaling adjustments in fast-moving species.

Studies using isolated plasma-vitelline membranes from Rana pipiens oocytes have shown that progesterone may act as a meiotic agonist by binding to the external loop sequence (QAATEEEPQN) between TM-1 and TM-2 helices of the $\alpha$-subunit (Morrill et al. 2008) and rapidly activate lipid enzymes such as $N$-methyl transferase and sphingomyelin synthase (Morrill et al. 2010). As shown in Table 2, both $H$. sapiens and $X$. laevis contain the putative progesterone binding site, whereas Hydra vulgaris and lower forms do not. Voltage-clamp measurements by Vedovato and Gadsby (2010), using intact Xenopus laevis oocytes indicate that the two C-terminal tyrosines (YY) of the $\alpha$-subunit stabilize $\mathrm{Na} / \mathrm{K}$-pump conformations. Deletion of the last five residues (KETYY) of the $\alpha$-subunit markedly lowers the apparent affinity for $\mathrm{Na}^{+}$activation of pump phosphorylation (Vedovato and Gadsby 2010). Table 2 further indicates that humans, frogs, and hydra all 
Fig. 2 A comparison of the domain topology of the $\mathrm{Na} / \mathrm{K}$ ATPase $\alpha$-subunits from Homo sapiens (top), Hydra vulgaris (middle), and Paramecium tetraurelia (PARTE, bottom) using the DomPred server (see "Methods" section). The vertical peaks and bars indicate the positions of domains within the peptide sequence. The ordinate represents the aligned termini profile and predicts the probability of the respective domains based on the DomPred algorithm

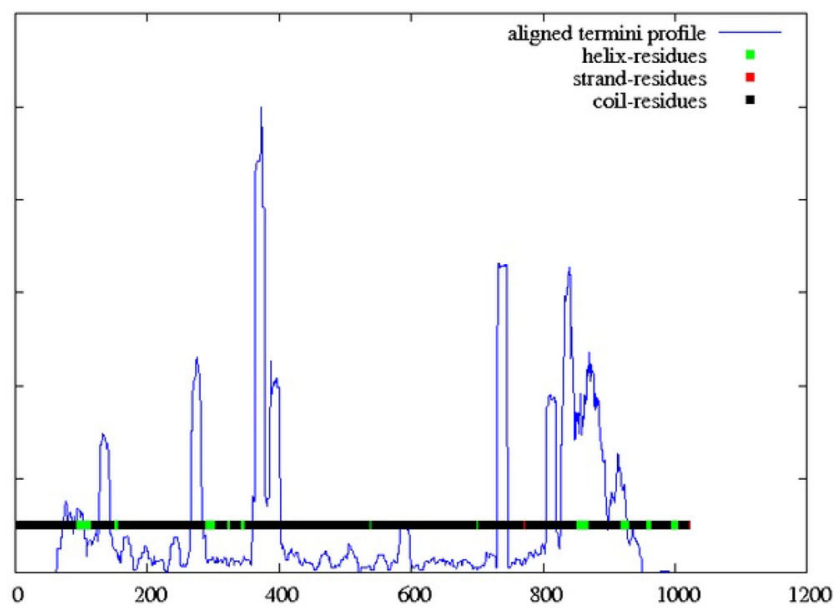

Homo sapiens ATP1A

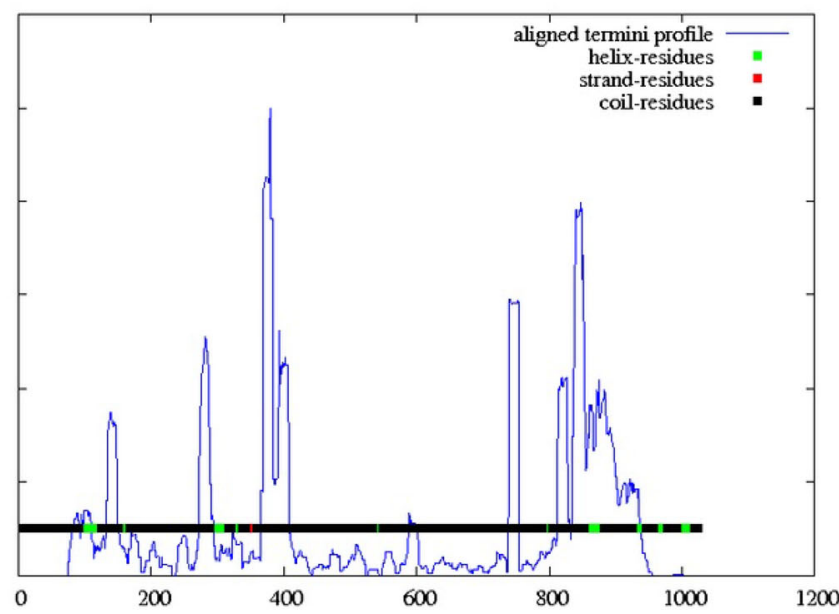

Hydra ATP1A

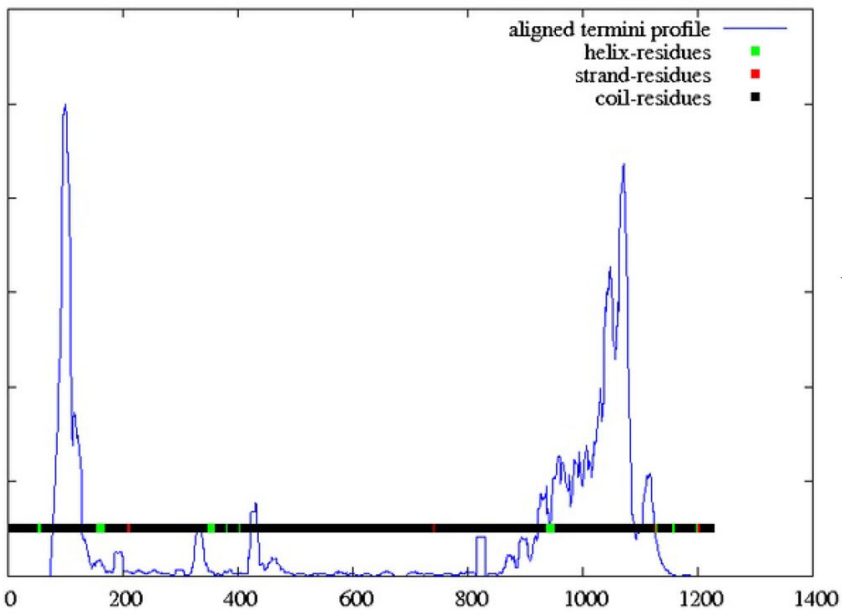

Paramecium ATP1A

contain the C-terminal KET(or S)YY contacts, whereas paramecia and the plasma membrane ion transporter ATPase of plant (Vicia faba) cells do not. This indicates that both the P13K1A-PDK-Akt pathway and the C-terminal YY residues play important roles in primitive multicellular species such as $H$. vulgaris (column 2), but not in lower species. Table 2 also indicates that progesterone binding does not contribute to $H$. vulgaris physiology, suggesting that a steroid response system(s) arose at a later stage of evolution. 
Table 2 Comparison of different regulatory systems associated with cell signaling in the Na/K-ATPase $\alpha$-subunit

\begin{tabular}{llll}
\hline $\begin{array}{l}\text { Na/K-ATPase } \alpha- \\
\text { subunit }\end{array}$ & $\begin{array}{l}\text { Activation of phosphatidylinositide } \\
\text { 3-Kinase 1A/Akt }\end{array}$ & $\begin{array}{l}\text { Putative progesterone cell surface binding } \\
\text { site first external loop }\end{array}$ & $\begin{array}{l}\text { C-terminal contacts that stabilize Na- } \\
\text { pump conformations }\end{array}$ \\
\hline $\begin{array}{l}\text { Homo sapiens } \\
\text { P05023 }\end{array}$ & ${ }^{81}$ TPPPTTP $^{87}$ & ${ }^{118}$ QAATEEEPQN $^{127}$ & KETYY $^{27}$ \\
$\begin{array}{l}\text { Xenopus laevis } \\
\text { Q92 } 123\end{array}$ & ${ }^{83}$ TPPPTTP $^{89}$ & ${ }^{119}$ QAAMEEEPQN $^{131}$ & KESYY \\
$\begin{array}{l}\text { Hydra vulgaris } \\
\text { P35317 }\end{array}$ & ${ }^{87}$ TPPKQTP $^{93}$ & ${ }^{125}$ AVRDTNPNM $^{133}$ & KETYY \\
$\begin{array}{l}\text { Paramecium } \\
\text { Q6BGF7 }\end{array}$ & ${ }^{78}$ APTNTKQ $^{84}$ & ${ }^{177}$ VNPEALGAKS $^{184}$ & ANSLW \\
$\begin{array}{l}\text { Beauveria } \\
\text { bassiana }\end{array}$ & ${ }^{69}$ NPLSWVM $^{75}$ & ${ }^{171}$ KVLGYVFGGFCSVLW $^{184}$ & AKIAW \\
J5JMV7 & & & \\
Vicia faba Q43131 & ${ }^{68}$ PSSPYTGI $^{75}$ & ${ }^{86}$ ANGGGQPPDWQ $^{96}$ & YKGNT \\
\hline
\end{tabular}

\section{Predicting Helix-Helix Interactions in the $\alpha$-Subunits Based on Residue Contacts}

Residue-residue contacts within the TM helices determine the three-dimensional topology of the $\alpha$-helical membrane proteins. Yang et al. (2013) have developed a method using the PSICOV algorithm to calculate correlated mutation scores. The ML-based engine was in turn merged with the CMA-based approach. Figure 3 illustrates the contact maps based on the top L/5 predictions for ATP1A1 of H. sapiens (top), H. vulgaris (middle), and P. tetraurelia (bottom). Contacts occurred in the 100 and 400 residue regions in all three species. Contacts increased markedly in the C-terminal region going from Paramecium to Hydra to $\mathrm{H}$. sapiens. In contrast, contacts decreased in the 900 residue region when Hydra was compared to Paramecium.

An approach developed by Nugent and Jones (2009, 2012) using the MEMPACK alpha-helical TM protein structure prediction server (http://bioinf.cs.ucl.ac.uk) allows comparison of the interactions between specific helices. Figure 4 illustrates helix-helix interactions between the first 4 helices in $H$. sapiens (top right), $H$. vulgaris (middle left), and Paramecium tetraurelia (bottom right). The cartoon illustrates the MEMSAT-SVM helix orientation and the predicted packing arrangement of the $\mathrm{N}$-terminal region. Colors in the MEMPACK cartoon indicate hydrophobic residues (blue), polar residues (red), and charged residues (green for negative, purple for positive). Lines between residues indicate a predicted interaction. As can be seen, all three species demonstrate significant interaction between TM-1 and TM-2. A further increase in helix-helix interactions between TM-1, TM-3, and TM-4 occurs in H. sapiens.

A comparison of the TM helix packing arrangements of the 6 C-terminal TM helices in Paramecium, Hydra, and $H$. sapiens indicates increasing TM helix-helix interactions in the $\alpha$-subunit of $\mathrm{Na} / \mathrm{K}$-ATPase, going from paramecium to humans (Fig. 5). Interactions between the six C-terminal helices of the domain-rich region of Paramecium are restricted to interactions between TM-5, TM-6, and TM-8. By comparison, Hydra demonstrates helix-helix interactions within all six helices with maximal interactions between TM-10 and both TM-7 and TM-8. H. sapiens demonstrate a similar extensive helix-helix interaction between TM-10 and TM-7 and TM-8, but no longer interact with TM-9.

\section{Comparison of Pore-Lining Regions, Hydrophobic Cores, and Disordered Regions in $\alpha$-Subunits of Several Species}

As noted in the Introduction, the protein structure of the $\alpha$ subunit of $\mathrm{Na} / \mathrm{K}$-ATPase is crucial in facilitating the passage of ions via channels across lipid bilayers. Typically, channel proteins contain a cavity (or pore) which spans the entire molecule with an opening on each side of the membrane. The pore often runs parallel to TM helices, forming the path along which ions travel, with adjacent compositional or structural features determining pore specificity (reviewed in Nugent et al. 2011). Nugent and Jones have developed methods to identify pore-lining regions in TM proteins from sequence information alone, which can then be used to determine pore stoichiometry (Nugent 2015). In addition, recent developments which identify functional sites in disordered regions can provide insight into their biochemical and cellular functions (Benito et al. 2002). Figure 6 compares the TM helix maps for H. sapiens (top), H. vulgaris (middle), and Paramecium tetraurelia (bottom). As defined in the annotations (bottom), predictions for TM helices are indicated as black 
Fig. 3 Comparisons of the contact maps based on the top L/5 predictions for ATP1A1 of Homo sapiens (top), Hydra vulgaris (middle), and Paramecium tetraurelia (bottom). Plots were obtained as described in "Methods" section

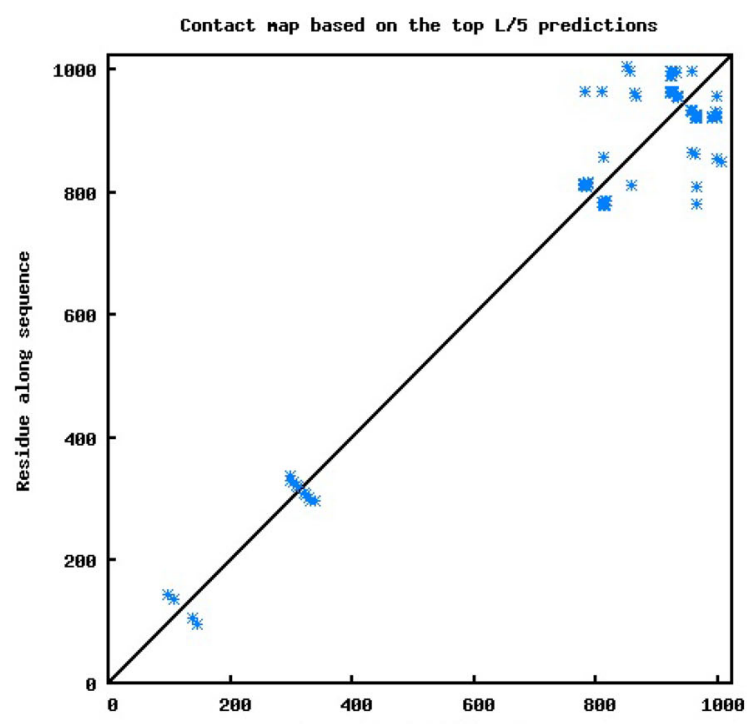

ATP1A1

Homo sapiens

Contact nap based on the top $L / 5$ predictions

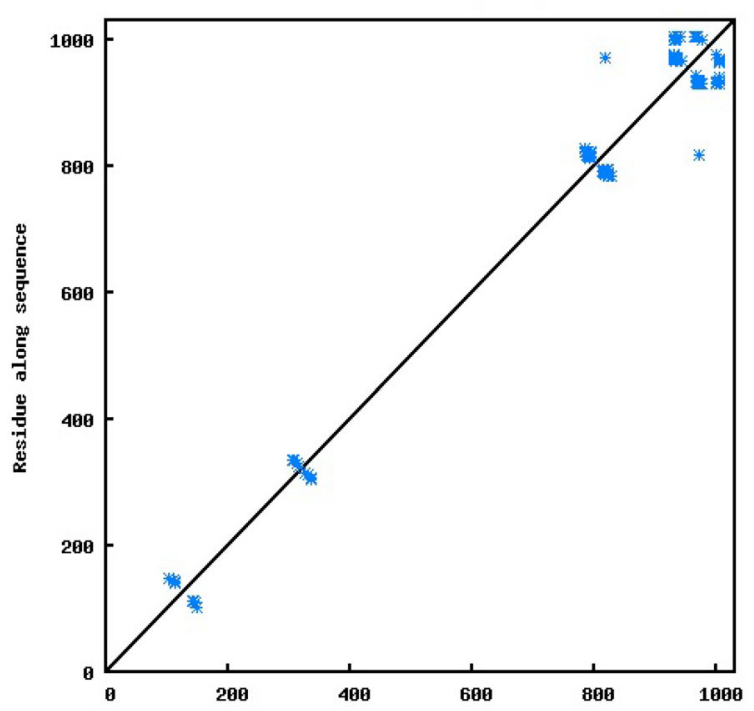

Contact nap based on the top $L / 5$ predictions

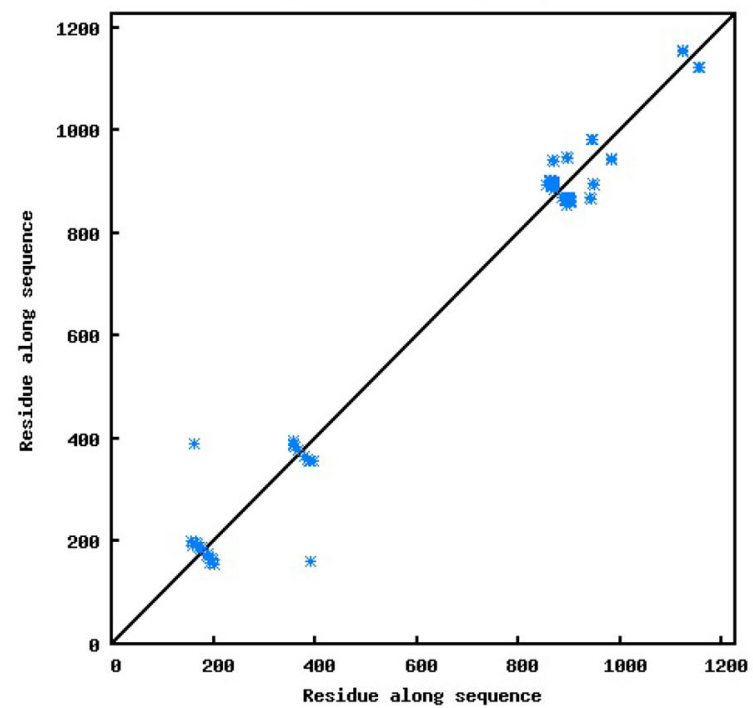

ATP1

Hydra vulgaris

ATP1

Paramecium tetraurelia 
Fig. 4 A comparison of four MEMPACK-SVM defined TM helices (TM-1-TM-4) in the $\mathrm{N}$-terminal regions of $\alpha$ subunits of Homo sapiens (top graphic, P05023), Hydra vulgaris (middle graphic, P35317), and Paramecium tetraurelia (bottom graphic, Q6BGF7). Colors in the MEMPACK cartoon indicate hydrophobic residues (blue), polar residues (red), and charged residues (green for negative, purple for positive). Lines between residues indicate predicted helix-helix interactions
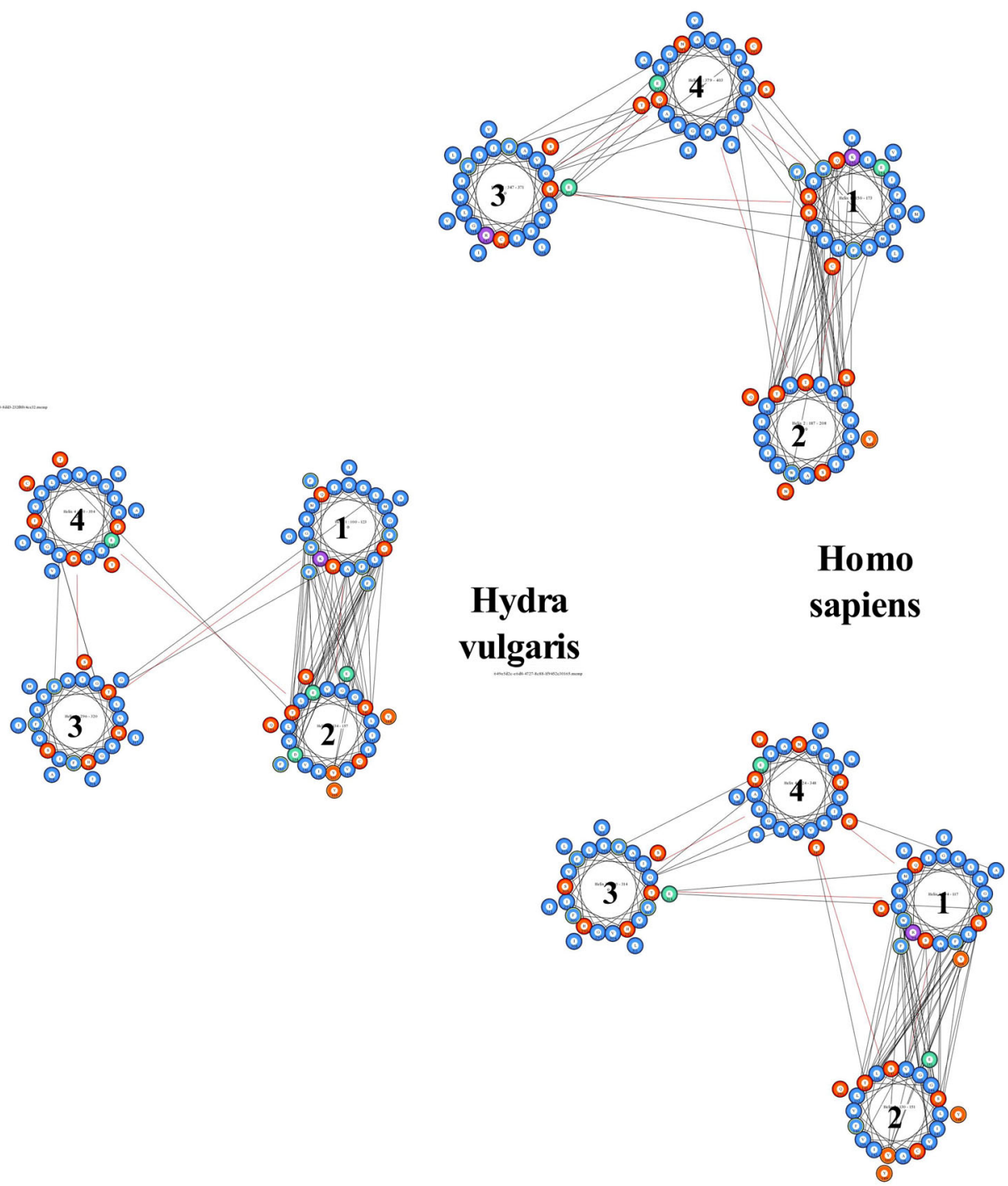

\section{Paramecium tetraurelia}

squares, pore-lining regions as blue squares, intracellular sequences are white, and extracellular sequences are orange. The disordered regions are identified by open boxes outlined in red (disordered) or green (disordered protein binding). As shown in Fig. 6, sequences previously identified as TM helices (TM-4, TM-5, TM-6, and TM-8) are identified as pore-lining regions in $H$. sapiens and Hydra. H. sapiens have several pore-lining regions in common with Hydra vulgaris (TM-4, TM-5, TM-6, TM-7 and TM-9). The major difference in topology occurs in the C-terminal region of $P$. tetraurelia. Figure 6 also indicates that the disordered regions are located in the cytoplasmic regions (open boxes with colored outlines in Fig. 6) and that disorder largely disappears between Paramecium and
Hydra, with a subsequent disappearance of disorder within the large intracellular loop between TM-4 and TM-5 as well as the $\mathrm{N}$-terminal region.

$\mathrm{K}^{+}$- or $\mathrm{Na}^{+}$-efflux ATPases are also key enzymes in the evolution of fungi (Benito et al. 2002). In fungi, a $\mathrm{Na}^{+} /-$ cation exchange system has evolved to compensate for elevated internal concentrations of $\mathrm{Na}^{+}$(reviewed in Benito et al. 2002). As shown in Fig. 7, analysis of the $\mathrm{Na}^{+} / \mathrm{K}^{+}$ATPase alpha 1 subunit of the fungus $B$. bassiana (J5JMV7) indicates that the $\alpha$-subunit has $10 \mathrm{TM}$ helices with the familiar pattern of two pairs in the $\mathrm{N}$-terminal region and a cluster of 6 helices in the C-terminal region (top graphic). MEMPACK analysis (bottom graphic) further indicates TM-4, TM-5, TM-6, and TM-8 are pore- 


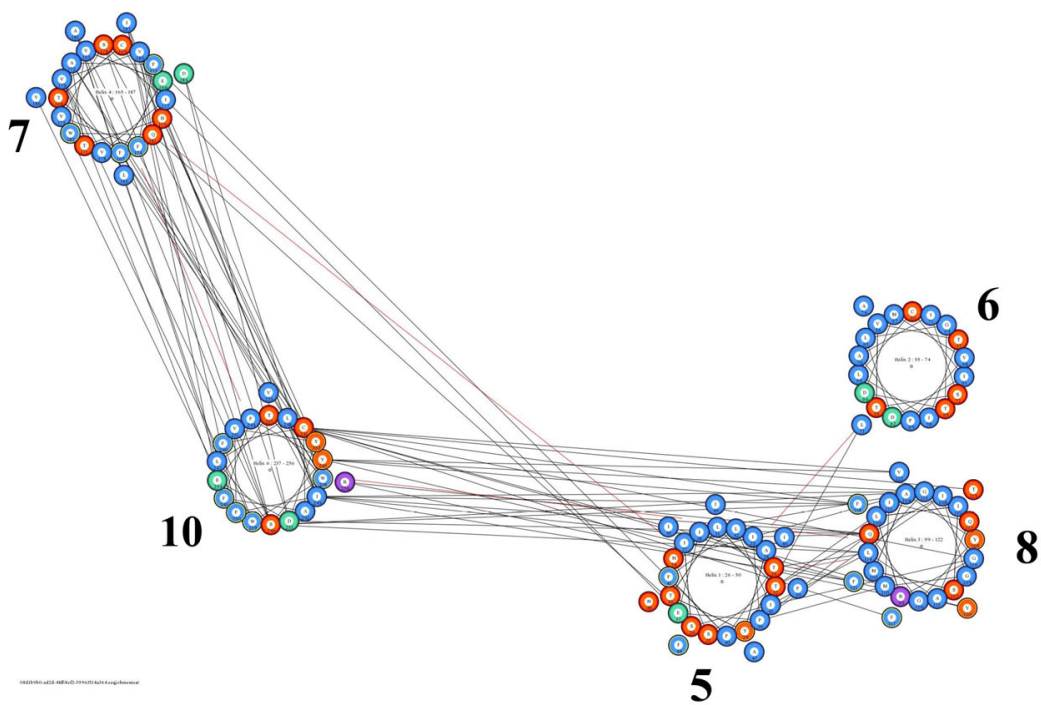

Homo sapiens

$9 \frac{0000}{8000}$

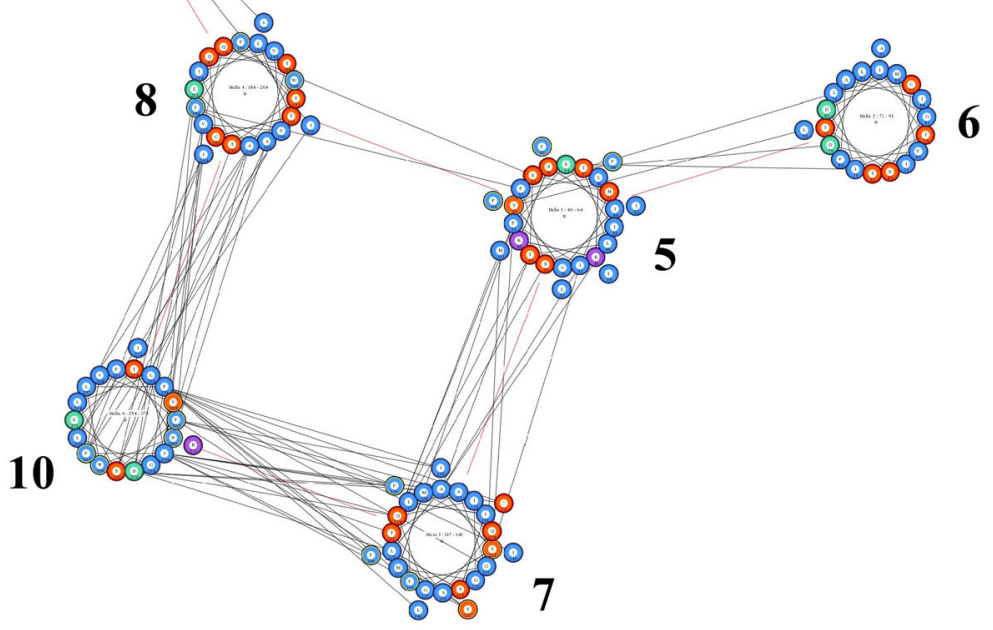

Hydra vulgaris

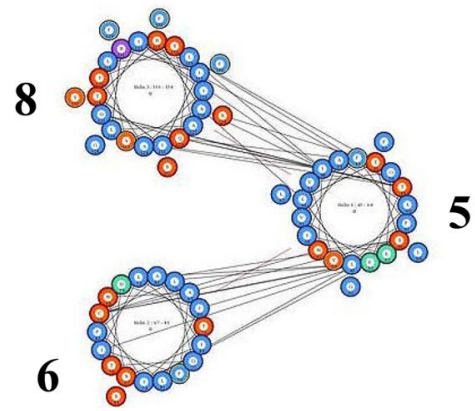

Paramecium tetraurelia 
4Fig. 5 A comparison of six MEMPACK-SVM defined TM helices (TM-5-TM-10) in the C-terminal region of $\alpha$-subunits of Homo sapiens (top graphic, P05023), Hydra vulgaris (middle graphic, P35317), Paramecium tetraurelia (bottom graphic, Q6BGF7). Predicted TM helices are indicated in black. Blue squares indicate predicted pore-lining regions. Extracellular regions (membrane loops) are in orange. See "Methods" section for details

lining regions in fungus. In comparison, TM-4, TM-5, TM6, and TM-9 are pore-lining regions in Paramecium (Fig. 6). Hydra and H. sapiens differ in that TM-8, not TM9 , is a pore-lining region. The domain topology of the fungus $B$. bassiana (middle graphic of Fig. 7) is much simpler than that seen for Paramecium, Hydra, or $H$. sapiens (Fig. 2). In Beauveria bassiana, identifiable protein domains are limited to residues 50-150.

It should be noted that about half of all TM helices are found to contain bends and other deviations, often referred to as "kinks" (Hall et al. 2009; Langelaan et al. 2010). As shown by Meruelo et al. (2011), distortions in helix geometry may facilitate conformational changes required for protein function by providing sites of flexibility (Bright et al. 2002; Shi et al. 2002) and can be important for positioning key residues precisely in the protein structure. Kinks that open the polar backbone to alternative hydrogen bonds often attract water molecules, thus providing a polar region within the hydrophobic core. Using TMKink to predict TM helix kinks in the $\alpha$-subunits, Table 3 indicates which of the ten TM helices (and/or pore-lining regions) contain kinks. As indicated, only two of the ten helices of Paramecia tetraurelia $(4,7)$ contain kinks, whereas eight of the ten helices $(1,2,3,4,7,8,9$, and 10) of Hydra contain kinks. In comparison, all four of $H$. sapiens $\mathrm{N}$-terminal TM helices $(1,2,3,4)$ contain kinks. There appears to be little correlation between kinks and pores. Only pore-lining region 4 contains a kink in all three species.

\section{Conclusions}

The emerging pattern suggests that the catalytic $\alpha$-subunit of $\mathrm{Na} / \mathrm{K}$-ATPase must have evolved as a result of the sequential introduction of protein domains within the C-terminal region of $\mathrm{a} \sim 1000$ residue precursor polypeptide. The $\alpha$-subunit of a fungus, $B$. bassiana exhibits a similar number of amino acid residues (1107 and 1023) and the same topology as that of H. sapiens; e.g., 2 pairs of TM helices in the $\mathrm{N}$-terminal region and a cluster of $6 \mathrm{TM}$ helices in the C-terminal region (Figs. 1, 6, 7). The TM helices and pore-lining regions (Figs. 6, 7) probably evolved early and the topology has remained unchanged over millions of years. A primary difference between Beauveria, Paramecium, and the early multicellular organism $(H$. vulgaris) is the progressive increase in the number and complexity of the protein domains (Figs. 2, 7).

The membrane potential of most fungal cells is about $-150 \mathrm{mV}$ [cf. (Shi et al. 2002)]. This high membrane potential is the driving force that supports the function of many uniporters, symporters, and antiporters that fungi have evolved to balance excessive $\mathrm{Na}^{+}$uptake. The limited distribution of protein domains to the $\mathrm{C}$-terminal region of fungi indicates that the uniporters, symporters, and/or antiporters are largely associated with protein domains within the first 250 residues of the $\mathrm{N}$-terminal region (compare Figs. 2, 7). Paramecia lack the classical Na/KATPase, since $\mathrm{K}^{+}$does not stimulate $\mathrm{Na}^{+}$efflux (Hansma 1979), consistent with the absence of the C-terminal KETYY sequence (Table 2). In Paramecium, ionic currents control swimming behavior (Eckert and Brehm 1979). When its membrane potential is at the resting level, Paramecium swims forward. When its membrane is hyperpolarized it swims backward. A closely related ciliate, Tetrahymena, also appears to lack a classical pump Na/ K-ATPase, since the specific inhibitor, ouabain, has no effect on $\mathrm{Na}^{+}$and $\mathrm{K}^{+}$transport (Dunham and Kropp 1983). The absence of the C-terminal KETYY sequence in both fungi and Paramecium (Table 2) is evidence for limited $\alpha$ subunit functionality in lower species.

As shown in Fig. 2, the catalytic subunit of a primitive multicellular organism, $H$. vulgaris, contains many of the protein domains characteristic of the ATP1A1 $\alpha$-subunit of $H$. sapiens, indicating that much of Na-pump evolution occurred during the development of multicellular organisms. The ectodermal epithelium of the fresh water $H$. vulgaris is the main site of ionic regulation in these organisms (Chain 1980). It actively transports $\mathrm{Na}^{+}$from the environment into the enteron and extracellular fluids, which are the two milieus that act as these animals' only "internal environment." A major step in electrical potential occurs across the inner ectodermal membrane; produced by an inwardly directed electrogenic pump which is sensitive to ethacrynic acid but not to ouabain (Chain 1980). As indicated in Table 2, the C-terminus of the H. vulgaris $\alpha$ subunit contains the moiety "KETYY," reported to be necessary for the $\mathrm{Na}^{+}$activation of pump phosphorylation from ATP in vertebrates (Vedovato and Gadsby 2010). The lack of "KETYY" in Paramecium and B. bassiana indicates that neither contains classical $\mathrm{Na}^{+} / \mathrm{K}^{+}$-pumps.

An important observation was that the introduction of multiple protein domains into the $\alpha$-subunit occurred during the evolution of primitive multicellular organisms (Fig. 2). Most protein domains were introduced within the 300-400 residue region containing TM-3 and TM-4 and to a lesser extent within the $800-900$ residue region 
TM Helix Map

Feature predictions are colour coded onto the sequence according to the sequence feature key shown below.

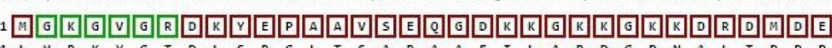

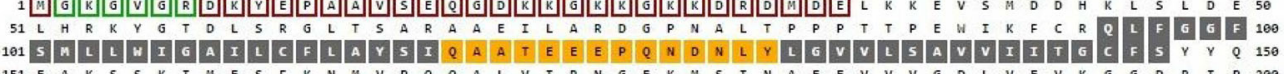

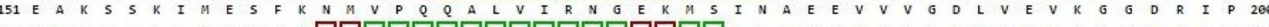

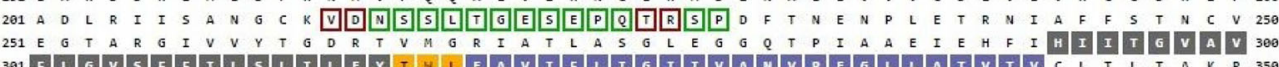

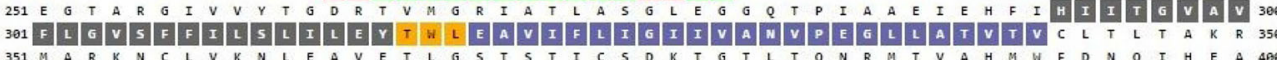
$\begin{array}{llllllllllllllllllllllllllllllllllllllllllllllllllll}351 & M & A & R & K & N & C & L & V & K & N & L & E & A & V & E & T & L & G & S & T & S & T & I & C & S & D & K & T & G & T & L & T & Q & N & R & M & T & V & A & H & M & N & F & D & N & Q & I & H & E & A & 460 \\ 401 & D & T & T & E & N & O & S & G & V & S & F & D & K & T & S & A & T & W & L & A & L & S & R & I & A & G & L & C & N & R & A & V & F & Q & A & N & O & E & N & L & P & I & L & K & R & A & V & A & G & D & 450\end{array}$

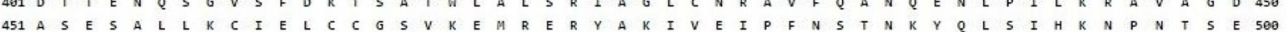
$501 P Q H L L V M K$ G A P E R I L D R C S S I L L H G K E Q P L D E E L K D A F Q Q N A Y L L E L G GLG E 550

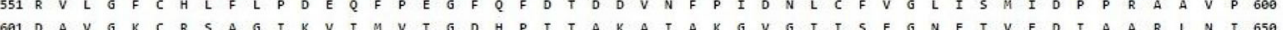
$\begin{array}{llllllllllllllllllllllllllllllllllllllllllllllllllll}601 & D & A & V & G & K & C & R & S & A & G & I & K & V & I & M & V & T & G & D & H & P & I & T & A & K & A & I & A & K & G & V & G & I & I & S & E & G & N & E & T & V & E & O & T & A & A & R & L & N & I & 65 \theta \\ 651 & P & V & S & Q & V & N & P & R & D & A & K & A & C & V & V & H & G & S & D & L & K & D & M & T & S & E & Q & L & D & D & I & L & K & Y & H & T & E & I & V & F & A & R & T & S & P & Q & Q & K & L & I & 700\end{array}$ 701 I V E E G C Q R Q G G A I V A V V T G G D G G V V N D D S P A

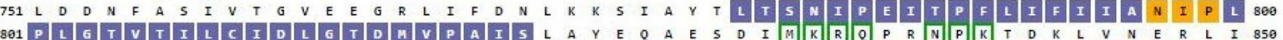

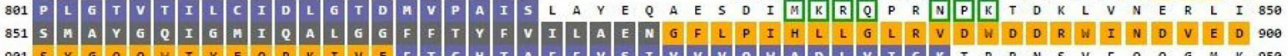

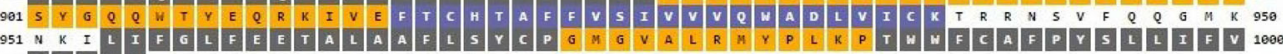

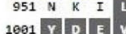

\begin{tabular}{|c|c|c|c|c|c|c|c|c|}
\hline KEY & $\begin{array}{l}\text { Transmembrane } \\
\text { Helix }\end{array}$ & $\begin{array}{l}\text { Pore lining } \\
\text { Helix }\end{array}$ & $\begin{array}{l}\text { Extracellular } \\
\text { Region }\end{array}$ & $\begin{array}{l}\text { Cytoplasmic } \\
\text { Region }\end{array}$ & Disordered & $\begin{array}{l}\text { Disordered } \\
\text { protein binding }\end{array}$ & $\begin{array}{l}\text { Dompred } \\
\text { Boundary }\end{array}$ & $\begin{array}{l}\text { DomSSEA } \\
\text { Boundary }\end{array}$ \\
\hline Annotations & m & [n & 1 & $\mathrm{i}$ & 口 & 回 & 조 & 미 \\
\hline
\end{tabular}

TM Helix Map

Feature predictions are colour coded onto the sequence according to the sequence feature key shown below.

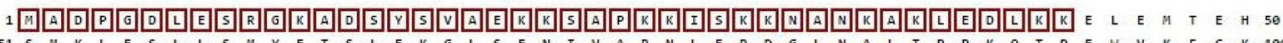

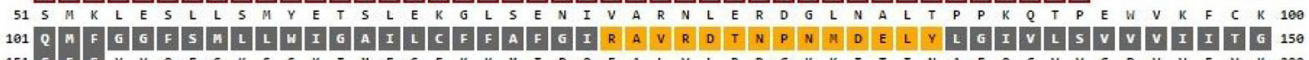
151 C F S Y Y Y Q E S K S S K I M E S F K K M I P Q E A L V L R D G K K I I T I N A E Q C C V V V G D V V V F V V K 200 $201 \mathrm{~F}$ G

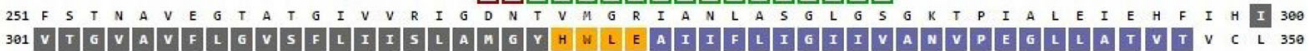

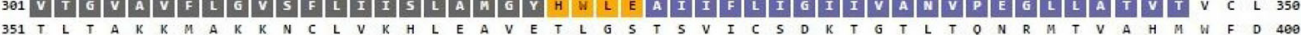
401 K M I V E A D T T E D O S G I A H D K G S L T W K S L A K V A A L C C S R A E E F K 451 K E G T G O A S E T A I L K F V E L S Y G N V M D I R A K N N K K K Y T E E I P F F N S S T N N K Y Q Q V V S V Y H E 500 5010 E

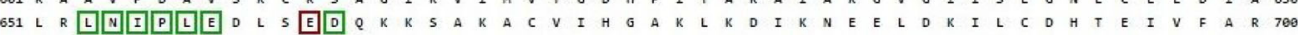
701 T S P Q Q K L I I V E G C Q R Q G A I V A V T G D G V N D S P P A L K K K A A D I I G V V A M M G I A G G

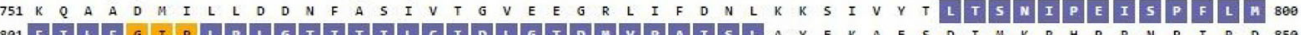
851 K L L V V N N E R R L I I S S L

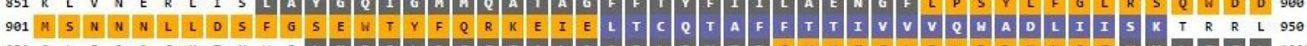

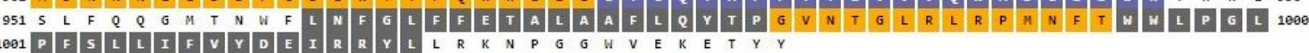

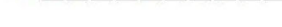

\begin{tabular}{|c|c|c|c|c|c|c|c|c|}
\hline KEY & $\begin{array}{l}\text { Transmembrane } \\
\text { Helix }\end{array}$ & $\begin{array}{l}\text { Pore lining } \\
\text { Helix }\end{array}$ & $\begin{array}{l}\text { Extracellular } \\
\text { Region }\end{array}$ & $\begin{array}{l}\text { Cytoplasmic } \\
\text { Region }\end{array}$ & Disordered & $\begin{array}{l}\text { Disordered } \\
\text { protein binding }\end{array}$ & $\begin{array}{l}\text { Dompred } \\
\text { Boundary }\end{array}$ & $\begin{array}{l}\text { DomSSEA } \\
\text { Boundary }\end{array}$ \\
\hline Annotations & 무 & 固 & 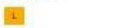 & 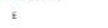 & 回 & 回 & 소 & D \\
\hline
\end{tabular}

TM Helix Map

Feature predictions are colour coded onto the sequence according to the sequence feature key shown below.

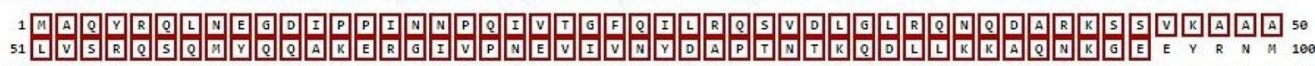

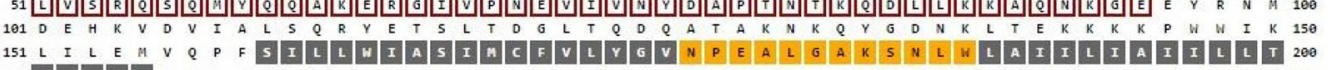
201 G S I I T T Y N Q S S A K A D A L M E G F K N F L P Q K K C I A I R G G G E K V V E V P P A E K L L V P G G O I I E I 251 K $M$ M G

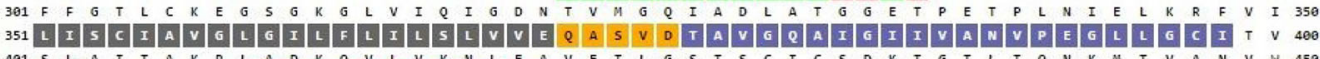

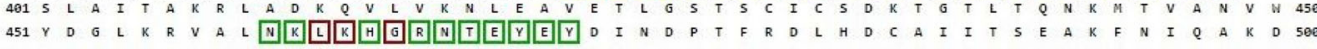

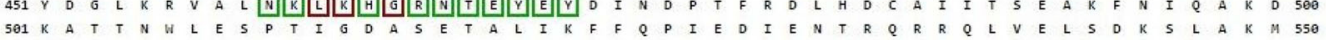
551 P F N S T N K F S L C I V N W E T Q D S F Y C V Y I K G A P E K L W T F S S Y

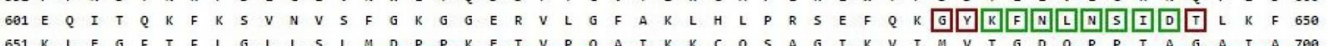

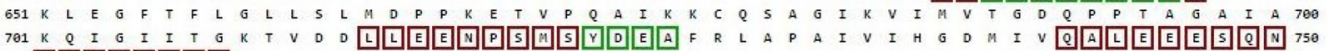
751 回国四国回四 K

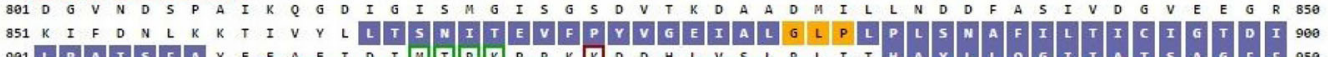

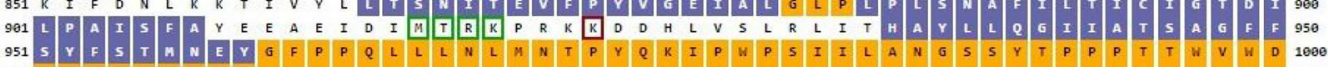

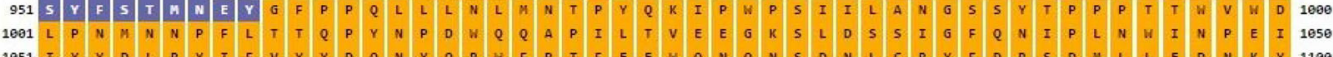

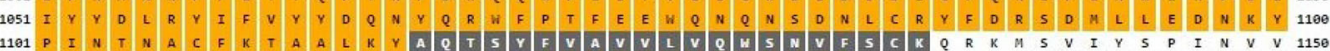

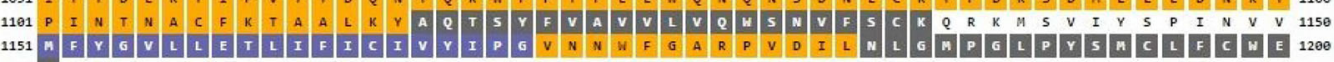
1201 E M R K Y Y F I R R N Y A K P S K Y

\begin{tabular}{|c|c|c|c|c|c|c|c|c|}
\hline KEY & $\begin{array}{l}\text { Transmembrane } \\
\text { Helix }\end{array}$ & $\begin{array}{l}\text { Pore lining } \\
\text { Helix }\end{array}$ & $\begin{array}{l}\text { Extracellular } \\
\text { Region }\end{array}$ & $\begin{array}{l}\text { Cytoplasmic } \\
\text { Region }\end{array}$ & Disordered & $\begin{array}{l}\text { Disordered } \\
\text { protein binding }\end{array}$ & $\begin{array}{l}\text { Dompred } \\
\text { Boundary }\end{array}$ & $\begin{array}{l}\text { DomSSEA } \\
\text { Boundary }\end{array}$ \\
\hline Annotations & n & 무 & 5 & $\varepsilon$ & 回 & 回 & 소 & 무 \\
\hline
\end{tabular}

\section{Paramecium tetraurelia}


4Fig. 6 Comparisons of the topology of TM helices, disordered regions, and pore-lining regions of $\mathrm{Na} / \mathrm{K}$-ATPase $\alpha$-subunit of Homo sapiens (upper plot), Hydra vulgaris (middle plot), and Paramecium tetraurelia (lower plot). Blue squares indicate predicted pore-lining regions and black squares, non-pore helix regions. Predicted TM helices are indicated in black. Blue squares indicate predicted porelining regions. Extracellular regions (membrane loops) are in orange. Disordered regions are indicated as open boxes outlined in either red (disordered) or green (Disordered protein binding). See "Methods" section for details

containing TM-5 and TM-6. As shown in Table 3, this region is associated with a marked increase in TM kinks. As noted above, Meruelo et al. (2011) suggest that TM kinks produce distortions in helix geometry and may be important for positioning key residues precisely within the protein structure, which together with amino acid sequence changes may lead to the formation of new protein domains. Analysis of caveolin-binding motifs (Table 4), known to be associated with membrane lipid rafts and cell signaling (Epand et al. 2005), reveal that significant positional shifts occur between Paramecium and H. vulgaris, indicating that regional membrane fluidity changes occur during evolution. Lipid rafts display reduced lateral diffusion relative to the lipid-disordered phase, thus providing nucleation sites for the further membrane organization to produce larger structures of 50-150 nm (reviewed in Epand et al. 2005). Table 4 also compares the locations of both caveolinbinding motifs and leucine-rich repeats in the catalytic subunits of $\mathrm{Na} / \mathrm{K}-\mathrm{ATPase}$ in Paramecium, Hydra vulgaris, and $H$. sapiens, as well as in X. laevis (Q92123) and the plant P-type ATP1 (Vicia faba, Q43131). Leucine-rich repeats are 20 to 29-residue sequence motifs present in proteins that appear to provide a structural framework for the formation of protein-protein interactions (Kobe and Kejava 2001). As shown for Paramecium, caveolin-binding motifs (CBMs) occur between TM-4 and TM-5 and between TM-7 and TM-8, whereas only one CBM occurs in Hydra which undergoes an apparent shift to overlap TM1 (column 2). The two higher species (Xenopus laevis and Homo sapiens) as well as a higher plant (Vicia faba) each contain two CBMs overlapping TM-1 and TM-10. In contrast, each leucine-rich repeat underwent changes in amino acid sequence but remained relatively fixed, overlapping TM-3 in all species.

The observations presented here indicate that a number of molecular traits of the $\mathrm{Na} / \mathrm{K}$-ATPase catalytic subunit became determined by the single-cell stage. These include protein sequence length, TM helix topology, and protein motifs such as the Leucine-rich repeats. Subsequent evolutionary changes appear to be due largely to introduction of protein domains into the catalytic subunits during evolution. A protein domain has been defined as a conserved part of a given protein sequence that can evolve, function, and exist independently (reviewed in Vogel et al. 2004). Each domain forms a compact three-dimensional structure and often can be independently stable and folded to create proteins serving different functions. Domains vary in length from about 25 amino acids to about 500 amino acids in length. Because they are independently stable, they may be exchanged between proteins leading to the evolution of protein families such as the P-type ATPases, which by the end of 2014 had 493 confirmed and unique members in the Swiss-Prot Database (George et al. 2004, Prosite motif PS00154). 
Fig. 7 Comparisons of the topology of TM helices (top graphic), protein domains (middle graphic), and disordered and pore-lining regions (lower graphic) of the $\mathrm{Na} / \mathrm{K}$-ATPase $\alpha$-subunit of Beauveria bassiana (strain ARSEF 2860, White

Muscardine disease fungus, \#J5JMV7). Blue squares indicate predicted pore-lining regions and black squares, nonpore helix regions. Predicted TM helices are indicated in black. Blue squares indicate predicted pore-lining regions. Extracellular regions (membrane loops) are in orange. Disordered regions are indicated as open boxes outlined in either red (Disordered) or green (Disordered protein binding). See Methods for details

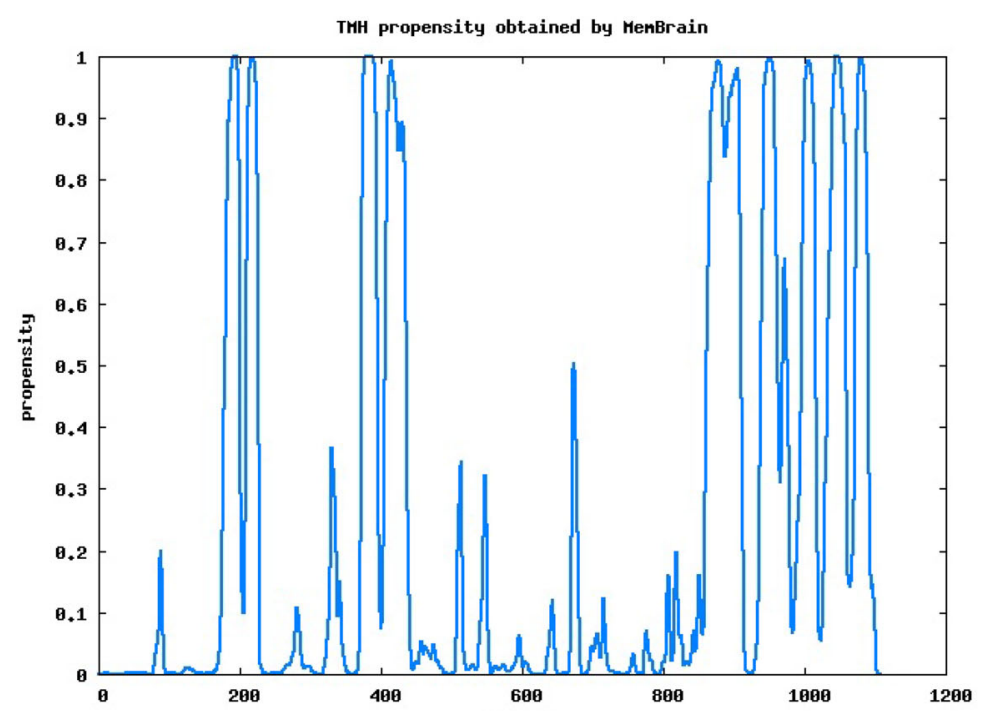

MemBrain
Helices

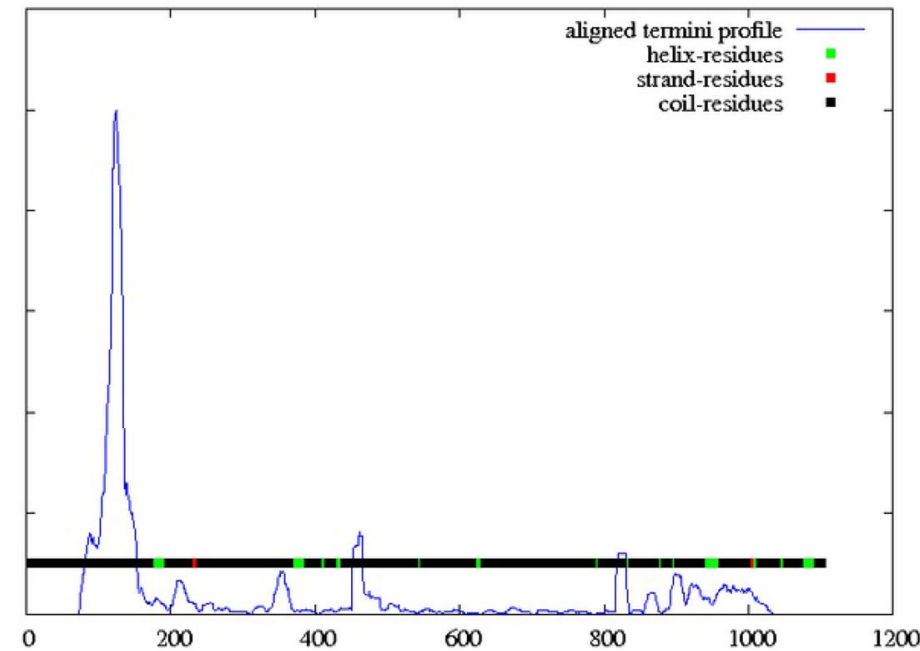

DomPred Domains

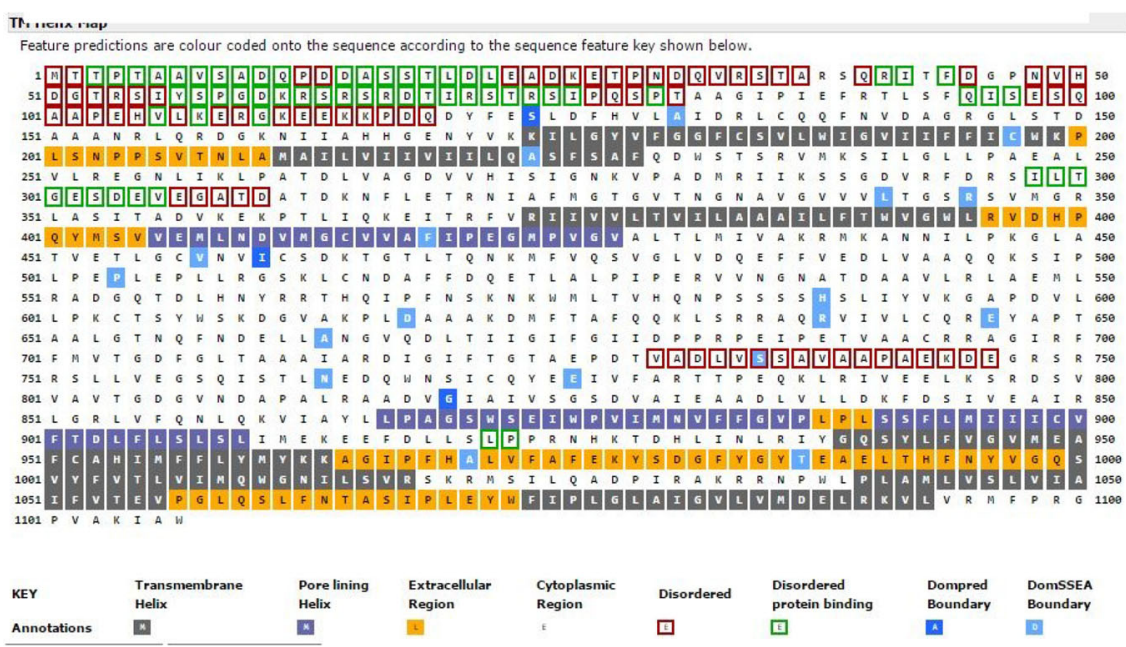

MEMPACK

Helices and Pore-

Lining Regions 
Table 3 Comparison of pore-lining regions and predicted kinks by position in Paramecia tetraurelia, Hydra vulgaris, and Homo sapiens

\begin{tabular}{|c|c|c|c|c|c|c|}
\hline \multirow[t]{2}{*}{ Transmembrane (TM) helix } & \multicolumn{2}{|c|}{ Paramecia tetraurelia } & \multicolumn{2}{|c|}{ Hydra vulgaris } & \multicolumn{2}{|c|}{ Homo sapiens } \\
\hline & TM kinks & Pore regions & TM kinks & Pore regions & TM kinks & Pore regions \\
\hline TM-1 & & & ${ }^{114} \mathrm{~A}-\mathrm{I}^{123}$ & & ${ }^{139} \mathrm{~V}-\mathrm{S}^{147}$ & \\
\hline TM-2 & & & ${ }^{145} \mathrm{~V}-\mathrm{S}^{153}$ & & ${ }^{275 S} \mathrm{~S}-\mathrm{A}^{285}$ & \\
\hline TM-3 & & & ${ }^{281} \mathrm{~S}-\mathrm{A}^{291}$ & & ${ }^{311} \mathrm{I}-\mathrm{A}^{320}$ & \\
\hline TM-4 & ${ }^{335} \mathrm{E}-\mathrm{I}^{343}$ & Pore & ${ }^{294} \mathrm{I}-\mathrm{I}^{300}$ & Pore & ${ }^{333} \mathrm{~V}-\mathrm{V}^{340}$ & Pore \\
\hline TM-5 & & Pore & & Pore & & Pore \\
\hline TM-6 & & Pore & & Pore & & Pore \\
\hline TM-7 & ${ }^{794} \mathrm{H}-\mathrm{K}^{810}$ & Pore & ${ }^{818} \mathrm{I}-\mathrm{S}^{829}$ & & & \\
\hline TM-8 & & & ${ }^{872} \mathrm{~A}-\mathrm{G}^{893}$ & Pore & & Pore \\
\hline TM-9 & & Pore & ${ }^{910} \mathrm{~F}-\mathrm{I}^{922}$ & & & \\
\hline TM-10 & & & ${ }^{957} \mathrm{M}-\mathrm{G}^{965}$ & & & \\
\hline
\end{tabular}

Table 4 Comparison of caveolin-binding motifs and leucine-rich repeat sequences in the $\alpha$-subunit of various animal and plant cells

\begin{tabular}{|c|c|c|}
\hline Species & Caveolin-binding motif & Leucine-rich repeat \\
\hline Homo sapiens (P05023) & $\begin{array}{l}{ }^{89}{ }_{\text {WIKFCRQLFGGFSMLLW }}{ }^{105} \text { Overlaps TM-1 } \\
{ }^{987} \text { WWFCAFPYSLLIFVY }^{100} 1 \text { Overlaps TM-10 }\end{array}$ & ${ }^{308}$ ILSLILEYTWL $^{318}$ \\
\hline Xenopus laevis (Q92123) & $\begin{array}{l}{ }^{91} \text { WVKFCRQLFGGF }^{102} \text { Overlaps TM-1 } \\
{ }^{989} \text { WWFCAFPYSLIIFIY1003 Overlaps TM-10 }\end{array}$ & ${ }^{310}$ ILSLILQYTWL ${ }^{320}$ \\
\hline Hydra vulgaris $(\mathrm{P} 35317)$ & ${ }^{95} \mathrm{WVKFCKQMFGGF}^{106}$ Overlaps TM-1 & ${ }^{303}$ GVAYFLGSFLI $^{314}$ \\
\hline Paramecium tetraurelia (Q6BGF7) & $\begin{array}{l}{ }^{650} \text { FKLEGFTF }^{657} \text { Between TM-4 and TM-5 } \\
{ }^{1052} \text { YYDLRYIFVYYDQNYQRW }^{1069} \text { Between TM-7 and TM-8 }\end{array}$ & ${ }^{369}$ LGILFLILSLVV $^{370}$ \\
\hline Vicia faba (Q43131) & $\begin{array}{l}{ }^{91} \text { WVKFCRQLFGGF }^{102} \text { Overlaps TM-1 } \\
{ }^{989} \text { WWFCAFPYSLIIFIY }^{1003} \text { Overlaps TM-10 }\end{array}$ & ${ }^{338}$ LNKISVDRNLI $^{348}$ \\
\hline
\end{tabular}

Acknowledgments This research was supported in part by National Institutes of Health research Grants HD-10463, GM-071324, and NHLBI Grant HL-36573.

Author contributions GM and AK conceived of the study. AA, RG, and LL contributed protein structural concepts and analyzed data, and GM wrote the paper. All authors read and approved the final manuscript.

\section{Compliance with Ethical Standards}

Conflict of Interest The authors declare that they have no conflict of interest.

Open Access This article is distributed under the terms of the Creative Commons Attribution 4.0 International License (http://creative commons.org/licenses/by/4.0/), which permits unrestricted use, distribution, and reproduction in any medium, provided you give appropriate credit to the original author(s) and the source, provide a link to the Creative Commons license, and indicate if changes were made.

\section{References}

Benito B, Garciadeblas B, Rodriguez-Navarro A (2002) Potassium- or sodium-efflux ATPase, a key enzyme in the evolution of fungi. Microbiology 148:933-941
Bernsal A, Viklund H, Hennerdal A, Elofsson A (2009) TOPCONS: consensus prediction of membrane protein topology. Nucleic Acid Res 37:W465-W468

Blanco G (2005) Na, K-ATPase subunit heterogeneity as a mechanism for tissue-specific ion regulation. Semin Nephrol 25:292-303

Bright JN, Shrivastava IH, Cordes FS, Sansom MS (2002) Conformational dynamics of helix S6 from Shaker potassium channel: simulation studies. Biopolymers 64:303-313

Bryson K, Cozzetto D, Jones DT (2007) Computer-assisted protein domain boundary prediction using DomPred server. Curr Protein Pept Sci 8:181-188

Bublitz M, Morth JP, Nissen P (2011) P-type ATPases at a glance. J Cell Sci 124:2515-2519

Chain BM (1980) The epithelial potential and osmotic regulation in the Green Hydra. J Exp Biol 88:161-173

Chan H, Babavan V, Blyumin E, Gandhi C, Hak K, Harake D, Kumar K, Lee P, Li TT, Liu HY, Lo TC, Meyer CJ, Standford S, Zamora KS, Saier MH Jr (2010) The p-type ATPase superfamily. J mol Microbiol Biotechnol 19(1-2):5-104

Cozzetto D, Jones DT (2013) The contribution of intrinsic disorder prediction to the elucidation of protein function. Curr Opin Struct Biol 23:467-472

Dunham PP, Kropp DL (1983) Regulation of solutes and water in Tetrahymena. In: Elliot AM (ed) Biology of Tetrahymena, Dowden, Hutchinson \& Ross, Stroudburg, p 165-199

Eckert R, Brehm P (1979) Ionic mechanisms of excitation in Paramecium. Annu Rev Biophys Bioeng 8:353-383

Epand RM, Sayer BG, Epand RF (2005) Caveolin scaffolding region and cholesterol-rich domains in membranes. J Mol Biol 345:339-350 
Gable ME, Abdallah SL, Najjar SM, Liu L, Askari A (2014) Digitalisinduced cell signaling by the sodium pump: on the relation of Src to $\mathrm{Na}(+) / \mathrm{K}(+)$-ATPase. Biochem Biophys Res Commun 446:1151-1154

Geering K (2008) Functional roles of Na, K-ATPase subunits. Curr Opin Nephrol Hypertens 17:526-532

George RA, Spriggs RV, Thornton JM, Lazikani B, Swindells MB (2004) SCOPEC: a database of protein catalytic domains. Bioinformatics 20(Suppl 1):i130-i136

Hall SE, Roberts K, Vaidehi N (2009) Position of helical kinks in membrane protein crystal structures and the accuracy of computational prediction. J Mol Graph Model 27:944-950

Hansma HG (1979) Sodium uptake and membrane excitation in Paramecium. J Cell Biol 81:374-381

Huang X, Miller W (1991) A time-efficient, linear-space local similarity algorithm. Adv Appl Math 12:337-357

Jones DT, Buchan DW, Cozzetto D, Pontil M (2012) PSICOV: precise structural contact prediction using sparse inverse covariance estimation on large multiple sequence alignments. Bioinfomatics 28:184-190

Kall L, Krogh A, Sonnhammer EL (2007) Advantages of combined transmembrane topology and signal peptide prediction-the Phobius web server. Nucleic Acid Res 35:W429-W432

Kaplan JH (2002) Biochemistry of Na, K-ATPase. Annu Rev Biochem 71:511-535

Kobe B, Kejava AV (2001) The leucine-rich repeat as a protein recognition motif. Curr Opin Struct Biol 11:725-732

Krogh A, Larsson B, von Heijne G, Sonnhammer EL (2001) Predicting transmembrane protein topology with a hidden Markov model: application to complete genomes. J Mol Biol 305:567-580

Langelaan DN, Wieczorek M, Blouin C, Rainey JK (2010) Improved helix and kink characterization in membrane proteins allows evaluation of kink sequence predictors. J Chem Inf Model 27:2213-2220

Meruelo AD, Samish I, Bowie JU (2011) TMKink: a method to predict transmembrane helix kinks. Protein Sci 20:1256-1264

Morrill GA, Kostellow AB, Askari A (2008) Progesterone binding to the alpha 1-subunit of the $\mathrm{Na} / \mathrm{K}$-ATPase on the cell surface: Insights from computational modeling. Steroids 73:27-40

Morrill GA, Kostellow AB, Askari A (2010) Progesterone modulation of transmembrane helix-helix interactions between the alphasubunit of $\mathrm{Na} / \mathrm{K}$-ATPase and phospholipid $\mathrm{N}$-methyltransferase in the oocyte plasma membrane. BMC Struct Biol. doi:10.1186/ 1472-6607-10-12

Mushegian A, Gurevich VV, Gurevich EV (2012) The origin and evolution of $\mathrm{G}$ protein-coupled receptor kinases. PLoS One 7(3):e33806

Nugent T (2015) De novo membrane protein structure prediction. Methods Mol Biol 1215:331-350

Nugent T, Jones DT (2009) Transmembrane protein topology prediction using support vector machines. BMC Bioinfomatics 10:159. doi:10.1186/1471-2105-10-159
Nugent T, Jones DT (2012) Detecting pore-lining regions in transmembrane protein sequences. BMC Bioinfomatics 13:169. doi:10.1186/1471-2105-13-169

Nugent T, Ward S, Jones DT (2011) The MEMPACK alpha-helical transmembrane protein structure prediction server. Bioinfomatics 27:1438-1439

Patel HH, Murray F, Insel PA (2008) G-protein-coupled receptorsignaling components in membrane raft and caveolar microdomains. Handb Exp Pharmacol 186:167-184

Reinhard L, Tidow H, Clausen MJ, Nissen P (2013) Na(+), K(+)ATPase as a docking station: protein-protein complexes of the $\mathrm{Na}(+), \mathrm{K}(+)$-ATPase. Cell Mol Life Sci 70:205-222

Richardson JS (1981) The anatomy and taxonomy of protein structure. Adv Protein Chem 34:167-339

Saez AG, Lozano E, Zaldivar-Riveron A (2010) Evolutionary history of $\mathrm{Na}, \mathrm{K}$-ATPases and their osmoregulatory role. Genetica 138:471-490

Shen H, Chou JJ (2008) MemBrain: improving the accuracy of predicting transmembrane helices. PLoS One 3(6):e2399

Shi Z, Woody RW, Kallenbach NR (2002) Is polyproline II a major backbone conformation in unfolded proteins? Adv Protein Chem 62:163-240

Thever MD, Saier MH Jr (2009) Bioinformatic characterization of p-type ATPases encoded within the fully sequenced genomes of 26 eukaryotes. J Membr Biol 229:115-130

Vedovato N, Gadsby DC (2010) The two C-terminal tyrosines stabilize occluded $\mathrm{Na} / \mathrm{K}$ pump conformation containing $\mathrm{Na}$ and K ions. J Gen Physiol 136:63-82

Viklund H, Bernsel A, Skwark M, Elofsson A (2008) SPOCTOPUS: a combined predictor of signal peptides and membrane protein topology. Bioinformatics 24:2928-2929

Vogel C, Bashton M, Kerrison ND, Chothia C, Teichmann SA (2004) Structure, function and evolution of multidomain proteins. Curr Opin Struct Biol 14:208-218

Weigand KM, Swarts HG, Fedosova NU, Russel FG, Koenderink JB (2012) Na, K-ATPase activity modulates Src activation: a role for ATP/ADP ratio. Biochim Biophys Acta 1818:1269-1273

Wetlaufer DB (1973) Nucleation, rapid folding, and globular interchain regions in proteins. Proc Natl Acad Sci USA 70:697-701

Wu J, Akkuratov EE, Bai Y, Gaskill CM, Askari A, Liu L (2013) Cell signaling associated with $\mathrm{Na}(+) / \mathrm{K}(+)$-ATPase: activation of phosphatidyl 3-kinase 1A/Akt by ouabain is independent of Src. Biochemistry 52:9059-9067

Xie Z, Askari A (2002) $\mathrm{Na}(+) / \mathrm{K}(+)$-ATPase as a signal transducer. Eur J Biochem 269:2434-2439

Yang J, Jang R, Zhang Y, Shen HB (2013) High-accuracy prediction of transmembrane inter-helix contacts and application to GPCR 3D structure modeling. Bioinfomatics 29:2579-2587

Yudowski GA, Efendley R, Pedemonte CH, Katz AI, Berggren P-O, Bertorello AM (2000) Phosphoinositide-3 kinase binds to a proline-rich motif in the $\mathrm{Na}+, \mathrm{K}+$-ATPase a subunit and regulates its trafficking. Proc Natl Acad Sci USA 97:6556-6561 